\title{
Indução de calos friáveis em explantes foliares de Salix (Salyx humboldtiana Willd)
}

\author{
Induction of friable callus in leaf explants of Salix (Salyx humboldtiana Willd)
}

\author{
Breno Régis Santos ${ }^{1}$ Renato Paiva ${ }^{2}$ Cristiano Martinotto ${ }^{3}$ \\ Raírys Cravo Nogueira ${ }^{4}$ Patrícia Duarte de Oliveira Paiva ${ }^{5}$
}

\section{RESUMO}

O salix é uma árvore ornamental adaptada a terrenos úmidos, sendo considerada uma espécie importante para a recomposição de áreas ciliares degradadas. A madeira pode ser empregada na indústria em geral. Apesar de produzir grande quantidade de sementes, estas não possuem alta percentagem de germinação. O presente trabalho teve como objetivo realizar o estabelecimento in vitro de salix através da indução e formação de calos friáveis em explantes foliares, visando a uma posterior regeneração de plantas para a propagação massal desta espécie. Explantes foliares foram inoculados em meio de cultura MS (MURASHIGE \& SKOOG, 1962), acrescido de diferentes concentrações de ácido 2,4diclorofenoxiacético $(0 ; 1,0 ; 2,0 ; 4,0 ; 6,0 ; 8,0 ; 10,0$ e 12,0mg L-1) $e$ combinações entre ácido naftalenoacético e benzilaminopurina, ambos em concentrações de 0,0; 1,0; 2,$0 ; 4,0 ; 6,0$ e $8,0 \mathrm{mg}^{-1}$. Os resultados demonstram que explantes inoculados na ausência de reguladores de crescimento não apresentam a formação de calos friáveis. Significativa produção de calos friáveis (90\%) é obtida utilizando-se 6,0mg $\mathrm{L}^{-1}$ de ácido 2,4-diclorofenoxiacético. A utilização de concentração individual de ácido naftalenoacético ou benzilaminopurina, além de induzir a calogênese, também foi capaz de promover rizogênese.

Palavras-chave: Salgueiro-do-rio, cultura de tecidos, calogênese, Salyx humboldtiana.

\section{ABSTRACT}

Salix is an ornamental tree adapted to humid soils being considered an important species used in depleted areas. Its wood may be used in all kinds of industries. Although the production of seeds is large, the germination is reduced. The objective of this work was to establish salix in vitro through the induction and formation of friable callus of leaf explants to provide future regeneration of plants for mass propagation of the species. Leaf explants were inoculated in MS medium (MURASHIGE \& SKOOG, 1962) supplemented with different concentrations of 2-4-diclorofenoxiacetic acid $(0 ; 1.0 ; 2.0$; $4.0 ; 6.0 ; 8.0$ and $12,0 \mathrm{mg} \mathrm{L}^{-1}$ ) and combinations of 1 naphthaleneacetic acid and 6-benzylaminopurine both with the concentrations of $0 ; 1.0 ; 2.0 ; 4.0 ; 6.0 \mathrm{e} 8.0 \mathrm{mg} \mathrm{L}^{-1}$. The results showed that explants inoculated in the absence of growth regulators had no formation of friable callus. Significant production of friable callus (90\%) was obtained with $6.0 \mathrm{mg}$ $L^{-1}$ of 2-4-diclorofenoxiacetic acid. Individual concentrations of 1-naphthaleneacetic acid or 6-benzylaminopurine induced callogenesis and rooting.

Key words: Salgueiro-do-rio, tissue culture, callogenesis, Salyx humboldtiana.

\section{INTRODUÇÃO}

O salix é uma árvore ornamental cuja madeira pode ser empregada na indústria em geral. A espécie é adaptada a terrenos úmidos, o que a caracteriza como uma espécie importante para a recomposição de áreas ciliares degradadas. Apesar de produzir grande quantidade de sementes de fácil

\footnotetext{
${ }^{1}$ Engenheiro Agrônomo MSc, Doutorando em Agronomia, Fisiologia Vegetal, Departamento de Biologia, Universidade Federal de Lavras (UFLA), Lavras, MG, Brasil. CP 37, 37200-000. E-mail: brenors@yahoo.com.br. Autor para correspondência.

${ }^{2}$ Engenheiro Agrônomo, Professor Adjunto, PhD, Departamento de Biologia, UFLA, Brasil.

${ }^{3}$ Engenheiro Agrônomo, Doutorando em Agronomia, Fisiologia Vegetal, Fisiologia Vegetal, Departamento de Biologia, UFLA, Brasil.

${ }^{4}$ Biólogo, MSc, Doutorando em Agronomia, Fisiologia Vegetal, Fisiologia Vegetal - Departamento de Biologia, UFLA, Brasil.

${ }^{5}$ Engenheiro Agrônomo, Doutor, Professor do Departamento de Agricultura, UFLA, Brasil.
} 
disseminação, as sementes do salix não possuem uma germinação eficiente. $\mathrm{O}$ baixo poder germinativo das sementes, associado ao potencial desta espécie para utilização em programas de preservação ambiental e sua utilização comercial, tornam o uso de técnicas de cultura de tecidos uma alternativa de propagação para o salix.

A cultura de tecidos é considerada uma técnica importante para a propagação de várias espécies lenhosas e vem sendo utilizada com sucesso (LANDA et al., 2000). A propagação por meio de cultura de tecidos pode ser feita por via direta ou indireta, esta última, via formação de calos que é considerada uma forma potencial de propagação em massa (PIERIK, 1987; LANDA et al., 2000). Estudos com calos devem ser desenvolvidos para determinar as condições de cultura que os explantes requerem para sobreviver e crescer (SIQUEIRA \& INOUE, 1992). O cultivo de calos pode ser utilizado para se estudar o desenvolvimento celular, explorar produtos provenientes do metabolismo primário e secundário, obter suspensão celular e propagação via formação de gemas ou embriões somáticos (LANDA et al., 2000). O uso de múltiplas brotações tem sido amplamente utilizado para a propagação em massa de diversas espécies, e que estas técnicas de cultura de tecidos têm sido geralmente realizadas através da formação de brotos, via calos (TSURO et al., 2000). Estas técnicas, em muitas espécies lenhosas, têm permitido a obtenção de calos, através dos quais é possível obter embriões somáticos e/ou induzir respostas morfogênicas capazes de produzir plântulas com características agronômicas desejáveis.

Espécies arbóreas nativas têm sido amplamente utilizadas em programas de revegetação de áreas degradadas de cerrados e matas ciliares requerendo uma produção contínua de um grande número de mudas. No entanto, algumas destas espécies apresentam sementes com algum tipo de dormência, dificultando sua propagação, tornando importante a obtenção de mudas via assexuada. Várias espécies nativas têm problemas com o baixo poder de germinação, muitas vezes são dormentes ou sem reservas. Assim, técnicas alternativas de propagação assexuada, como a cultura de tecidos, devem ser estudadas para se obter um número expressivo de mudas de espécies ecológica e comercialmente importantes.

O objetivo foi realizar o estabelecimento in vitro de salix através da indução e formação de calos friáveis em explantes foliares, visando a uma posterior regeneração de plantas para a propagação massal desta espécie.

\section{MATERIAL E MÉTODOS}

Foram utilizados como explantes tecidos foliares jovens, com tamanho aproximado de $1,0 \mathrm{~cm}^{2}$, retirados de plantas matrizes com quatro meses de idade, mantidas em viveiro telado com sombrite $50 \%$ sob irradiância natural de $600 \mu \mathrm{mol} \mathrm{s}^{-1} \mathrm{~m}^{-2}$.

Após a coleta, as folhas foram mantidas em água corrente por um período de 24 horas. A desinfestação das mesmas foi realizada em câmara de fluxo laminar utilizando-se álcool 70\% (v/v) por 20 segundos e hipoclorito de sódio comercial da marca Q-boa ${ }^{\circledR}$, a $0,5 \% \mathrm{v} / \mathrm{v}$ do cloro residual total, durante 20 minutos. Após a desinfestação, as folhas foram enxaguadas três vezes em água destilada e autoclavada. Subseqüentemente, os explantes foram extraídos e inoculados em meio de cultura MS (MURASHIGE \& SKOOG, 1962), com a adição de $30 \mathrm{~g}$ $\mathrm{L}^{-1}$ de sacarose e de diferentes concentrações de ácido 2,4-diclorofenoxiacético $(0 ; 1,0 ; 2,0 ; 4,0 ; 6,0 ; 8,0 ; 10,0$ e $\left.12,0 \mathrm{mg} \mathrm{L}^{-1}\right)$ e combinações entre o ácido naftalenoacético e benzilaminopurina, ambos em concentrações de 0,$0 ; 1,0 ; 2,0 ; 4,0 ; 6,0$ e $8,0 \mathrm{mg} \mathrm{L}^{-1}$. O $\mathrm{pH}$ do meio de cultura foi ajustado para 5,8, antes da adição de $7 \mathrm{~g} \mathrm{~L}^{-1}$ de ágar da marca Merck ${ }^{\circledR}$. Em seguida, alíquotas de $15 \mathrm{~mL}$ do meio foram distribuídos em tubos de ensaio $(2,5 \mathrm{~cm} \times 15 \mathrm{~cm})$, os quais foram posteriormente fechados com tampas de polipropileno. A autoclavagem do meio foi a $120^{\circ} \mathrm{C}$ e 1,5 atm por 15 minutos.

Os tratamentos foram dispostos em delineamento inteiramente casualizado com vinte repetições por tratamento, sendo cada repetição composta por um tubo de ensaio contendo um explante. Os dados das variáveis do efeito do ácido 2,4-diclorofenoxiacético foram analisados por meio de regressão polinomial.

Após a inoculação, os explantes foram mantidos em sala de crescimento, sob fotoperíodo de 16 horas, temperatura de $25 \pm 2^{\circ} \mathrm{C}$ e irradiância de $13 \mu \mathrm{mol} \mathrm{s}{ }^{-1} \mathrm{~m}^{-2}$ fornecida por lâmpadas fluorescentes, luz do dia. Aos 35 dias da inoculação, foi avaliado o percentual de explantes com calos e matéria fresca dos mesmos. Os efeitos isolados e em conjunto de ácido naftalenoacético e benzilaminopurina foram estudados pela regressão polinomial.

\section{RESULTADOS E DISCUSSÃO}

A porcentagem de explantes com formação de calo apresentou um modelo quadrático (Figura 1), podendo-se verificar que aumentos na concentração de ácido 2,4-diclorofenoxiacético até $6,0 \mathrm{mg} \mathrm{L}^{-1}$ 


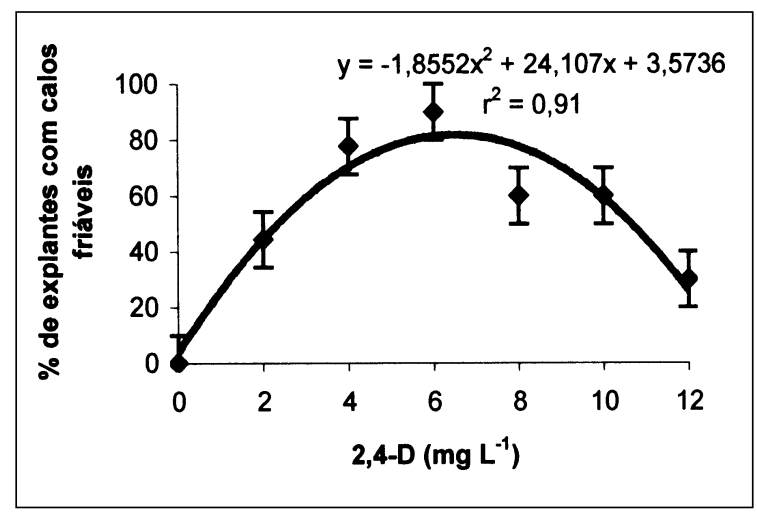

Figura 1 - Efeito de diferentes concentrações de ácido 2,4diclorofenoxiacético na formação de calos friáveis em explantes foliares de salix.

promoveram um aumento crescente na porcentagem de explantes que formaram calos friáveis. A maior porcentagem (aproximadamente $90 \%$ ) de explantes com calos ocorreu, quando se adicionou ao meio de cultura $6,0 \mathrm{mg} \mathrm{L}^{-1}$ desta auxina. Estudos realizados com Smilax japecanga (SANTOS et al, 1997) e Coffea arábica (FORNI, 1993), também reportam o efeito isolado do ácido 2,4-diclorofenoxiacético na formação de calos em explantes foliares. Em ambas as espécies, concentrações do ácido 2,4-diclorofenoxiacético entre 2,0 e $5,45 \mathrm{mg} \mathrm{L}^{-1}$ proporcionam maior indução de calos friáveis. Para o salix, concentrações superiores a $6,0 \mathrm{mg}$ $\mathrm{L}^{-1}$ inibiram a indução de calos nos explantes, sendo que, ao se adicionarem $12,0 \mathrm{mg} \mathrm{L}^{-1}$ de ácido 2,4diclorofenoxiacético ao meio de cultivo, observou-se uma redução de $60 \%$ em relação à utilização de $6,0 \mathrm{mg}$ $\mathrm{L}^{-1}$. Esses resultados estão de acordo com TORRES \& CALDAS (1990), os quais afirmam que concentrações elevadas de auxinas podem inibir, dependendo da espécie, a formação de calos friáveis em tecidos foliares.

Comportamento semelhante ao verificado para número de explantes com formação de calo foi observado para a matéria fresca de calo (Figura 2). Concentrações crescentes até $6,0 \mathrm{mg} \mathrm{L}^{-1}$ foram claramente benéficas e concentrações superiores a esta reduziram a matéria fresca dos calos. Ao comparar as concentrações de $6,0 \mathrm{mg} \mathrm{L}^{-1} \mathrm{com} 12,0 \mathrm{mg} \mathrm{L}^{-1}$ de ácido 2,4-diclorofenoxiacético, verificou-se uma redução de aproximadamente $60 \%(0,86 \mathrm{~g}$ contra aproximadamente $0,35 \mathrm{~g}$ ) na matéria fresca de calos.

A redução da matéria fresca dos calos com a utilização de concentrações elevadas do ácido 2,4diclorofenoxiacético pode estar relacionada à fitotoxidez causada por este regulador de crescimento. Esse comportamento também foi observado por

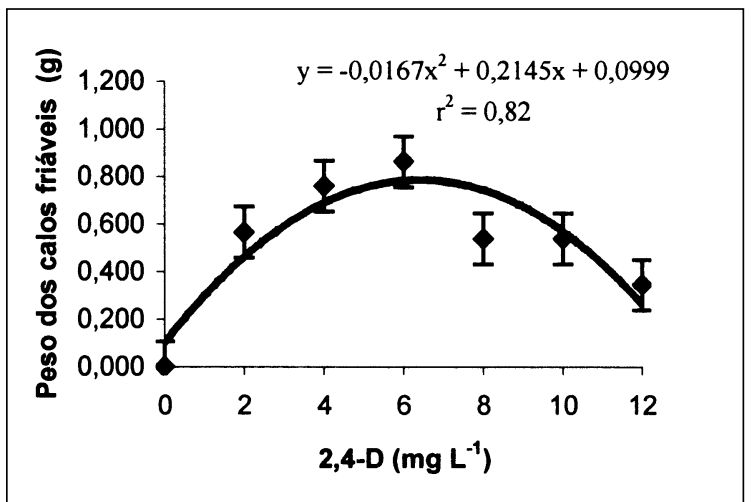

Figura 2 - Efeito de diferentes concentrações de ácido 2,4-diclorofenoxiacético na matéria fresca de calos friáveis formados em explantes foliares de salix.

MESQUITA (1999) em calos formados em explantes foliares de lechieira (Litchi chinensis) inoculados na presença de concentrações elevadas de ácido 2,4diclorofenoxiacético.

O uso isolado de ácido naftalenoacético também promoveu a formação de calos friáveis em explantes foliares de salix. A utilização de 3,5 a $4,5 \mathrm{mg} \mathrm{L}^{-1}$ desta auxina promoveu a formação de calos em aproximadamente $70 \%$ dos explantes e concentrações superiores inibiram esta formação (Figura 3A). Ao contrário, o uso isolado de benzilaminopurina inibiu a formação de calos (Figura 3B). A utilização individual de ácido naftalenoacético ou benzilaminopurina também foi capaz de promover rizogênese. Resultados semelhantes foram obtidos por PAIVA NETO et al. (1997) com relação à auxina. Estes autores induziram rizogênese em explantes foliares de salix utilizando ácido indolbutírico e ácido naftalenoacético. Ademais, observaram que concentrações superiores a $1,5 \mathrm{mg} \mathrm{L}^{-1}$ inibiram a formação de raízes em aproximadamente $38 \%$ dos explantes. Com relação ao efeito da benzilaminopurina na rizogênese, não foram encontrados na literatura consultada dados para confrontar nossos resultados.

Embora o uso isolado de ácido naftalenoacético ou benzilaminopurina tenha sido capaz de induzir a formação de raízes em segmentos foliares de salix, a combinação destes reguladores induziu somente a formação de calos. Não houve a formação de calos na ausência de reguladores de crescimento (Figura 4). Utilizando concentrações reduzidas de ácido naftalenoacético, maior formação de calos friáveis foi obtida, na presença de concentrações de benzilaminopurina acima de $4,0 \mathrm{mg} \mathrm{L}^{-1}$. Utilizando quantidades reduzidas de benzilaminopurina, observou- 


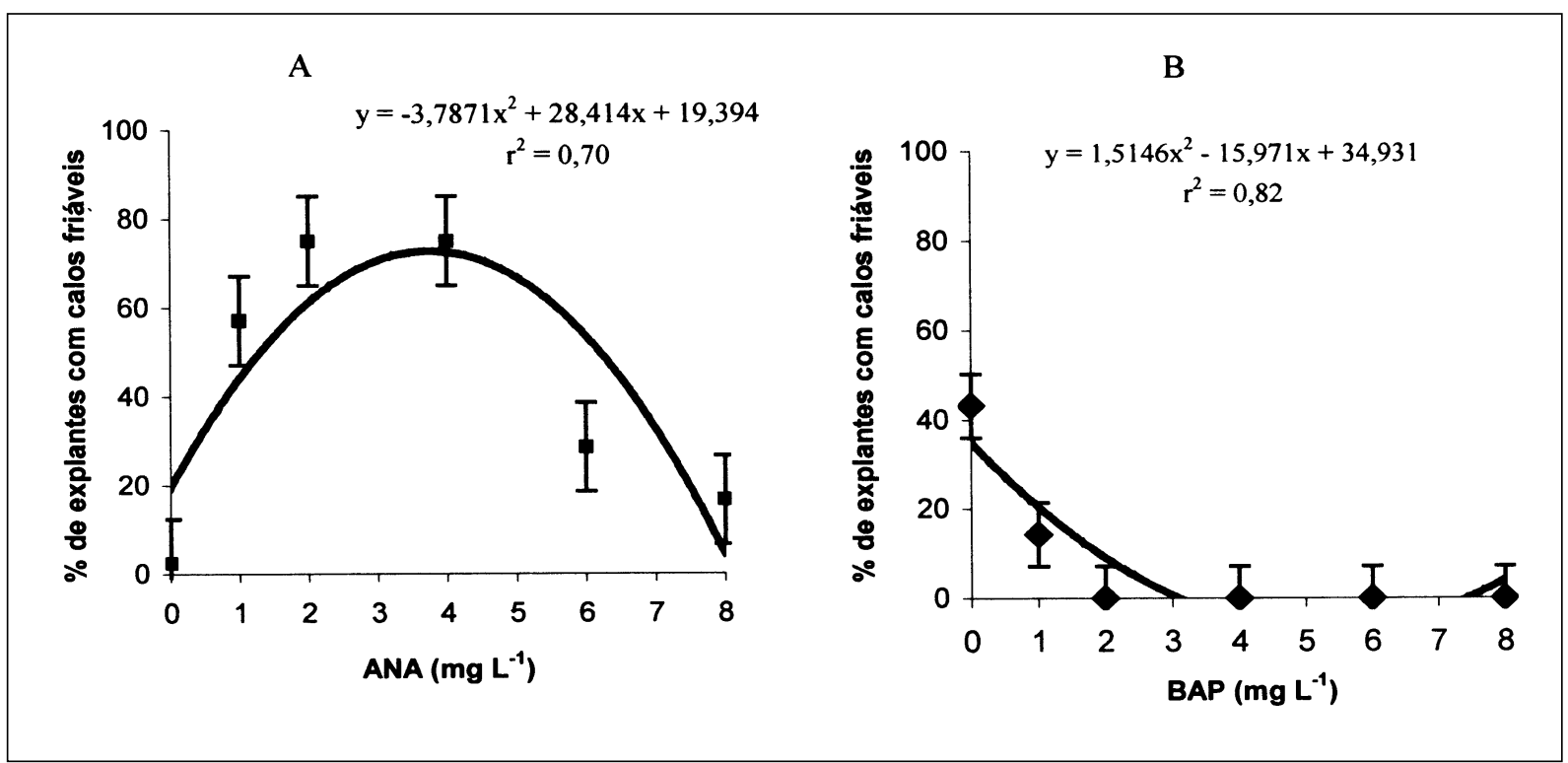

Figura 3 - Efeito de diferentes concentrações de ácido naftalenoacético (A) e benzilaminopurina (B) no número percentual de explantes foliares de salix apresentando formação de calos.

se maior formação de calos friáveis na presença de concentrações de ácido naftalenoacético acima de $6,0 \mathrm{mg} \mathrm{L}^{-1}$. O efeito positivo da combinação entre o ácido naftalenoacético e benzilaminopurina na formação de calos também foi observada por LANDA et al. (2000), os quais induziram calogênese em explantes foliares de pequizeiro (Caryocar brasiliense Camb.) utilizando 2,0 $\mathrm{mg} \mathrm{L}^{-1}$ de ácido naftalenoacético e $1,0 \mathrm{mg} \mathrm{L}^{-1}$ de benzilaminopurina, obtendo aproximadamente $91 \%$ de formação de calos. Resultados semelhantes também foram observados em moreira (Maclura tinctoria), uma espécie nativa que apresenta dificuldade de propagação

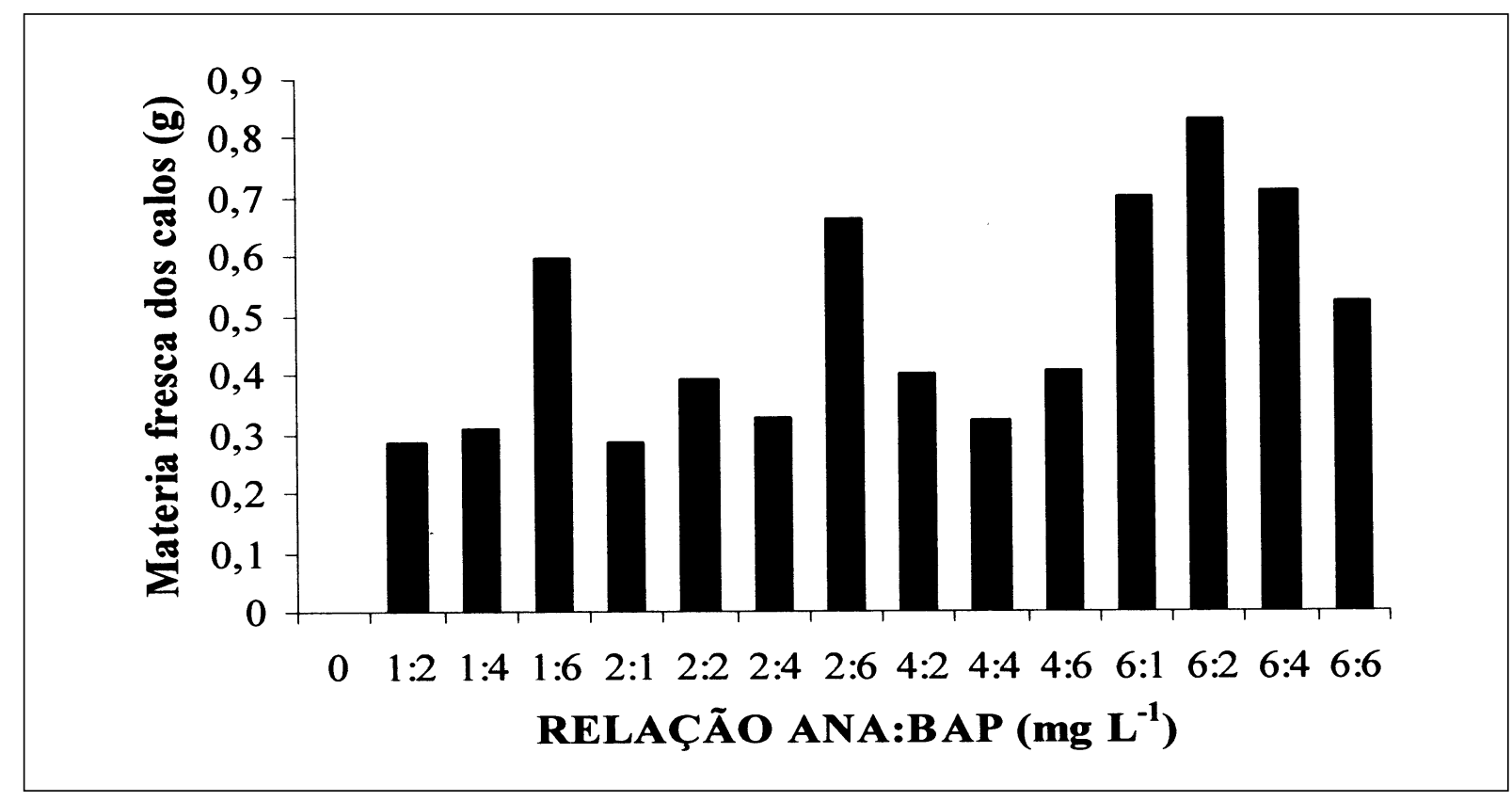

Figura 4 - Efeito de diferentes combinações de ácido naftalenoacético e benzilaminopurina sobre a matéria fresca de calos friáveis formados em explantes foliares de salix.

Ciência Rural, v.35, n.3, mai-jun, 2005. 
sexuada, quando se observou o efeito positivo da combinação entre auxinas e citocininas na indução de calos em segmentos foliares (GOMES, 1999).

\section{CONCLUSÕES}

Explantes foliares de salix inoculados em meio MS, desprovido do ácido 2,4-diclorofenoxiacético e ácido naftalenoacético não apresentam formação de calos friáveis, sendo que uma produção significativa de calos friáveis (90\%) é obtida utilizando-se $6,0 \mathrm{mg} \mathrm{L}^{-1}$ de ácido 2,4-diclorofenoxiacético. Através da utilização de concentração individual de ácido naftalenoacético ou benzilaminopurina, é possível induzir a formação de calos e de raízes. Para uma maior formação de calos friáveis deve-se utilizar concentrações reduzidas de ácido naftalenoacético e concentrações de benzilaminopurina acima de 4,0mg L $\mathrm{m}^{-1}$. O uso de benzilaminopurina em concentrações reduzidas deve ser acompanhado de concentrações de ácido naftalenoacético acima de $6,0 \mathrm{mg}$ $\mathrm{L}^{-1}$, para a obtenção de calos friáveis.

\section{REFERÊNCIAS BIBLIOGRÁFICAS}

FORNI, R.C. Níveis de "MS", BAP, número de gemas do explante e período de repicagem na produção de brotos, folhas, matéria seca e níveis de 2,4-D e cinetina para tamanho e fenótipo dos calos de Coffea arábica L. cv. Catuaí Vermelho CH 2077-2-5-44. 1993. 81f. Dissertação (Mestrado em Fitotecnia) - Universidade Federal de Lavras.

GOMES, G.A.C. Propagação in vitro de Moreira (Maclura tinctoria). 1999. 92f. Dissertação (Mestrado em Fisiologia Vegetal) - Universidade Federal de Lavras.
LANDA, F.S.L. et al. Indução in vitro de calos em explantes foliares de pequizeiro (Caryocar brasiliense Camb.). Ciência e Agrotecnologia, Lavras, v.24 (Edição Especial), p.56-63, 2000 .

MESQUITA, A.C. Estabelecimento in vitro de lechieira (Litchi chinensis Sonn.) através do cultivo de segmentos foliares e nodais e análise bioquímica de calos. 1999. 67f Dissertação (Mestrado em Fisiologia Vegetal) Universidade Federal de Lavras.

MURASHIGE, T.; SKOOG, F. A revised medium for rapid growth and bioassays with tobacco cultures. Physiologia Plantarum, Copenhagen, v.15, p.473497, 1962 .

PAIVA NETO, V.B. et al. Comportamento in vitro de segmento nodal de moreira (Chlorophora tinctoria (L.) Gaudichaud). Arquivos de Biologia e Tecnologia, Curitiba, v.40, n.1, p.135-141, 1997.

PIERIK, R.L.M. In vitro culture of higher plants. Boston: Martinus Nijhoff Publishers, 1987.

SANTOS, M.R.A.et al. Cultura de tecidos de Smilax japecanga Grisebach: indução e crescimento de calos. Ciência Agronômica, Fortaleza, v.28, p.37-43, 1997.

SIQUEIRA, E.R. de; INOUE, M.T. Propagação vegetativa do coqueiro através da cultura de tecidos. Pesquisa Agropecuária Brasileira. Brasília, v.27, n.4, p.639-646, 1992.

TORRES A.C.; CALDAS L.S. Técnicas e aplicações da cultura de tecidos de plantas. Brasília : ABCTP/ EMBRAPA-CNPH, 1990. 433p.

TSURO, M. et al. Efficient plant regeneration from multiple shoots formed in the leaf-derived callus of Lavandula vera, using the "open culture system". Scientia Hortculturae, v.86 p.81-88, 2000. 